\title{
Kinetic OF BAtch Production OF LACTIC ACID FRoM CAROB PODS SYRUP
}

\author{
Bouhadi Djilali $^{1 *}$, Hariri Ahmed ${ }^{1}$, Ould Yerou Karima ${ }^{1}$, Benattouche Zouaoui ${ }^{1}$, \\ Sahnouni Fatima ${ }^{2}$ and Mohmed Hadjari ${ }^{1}$ \\ ${ }^{1}$ Bioconversion Laboratory, Microbiology Engineering and Health Safety, Faculty of Science the Nature \\ and Life, University of Mascara, Mascara 29000, Algeria \\ ${ }^{2}$ Environmental Monitoring Network, Faculty of Science, University of Oran 31030, Algeria \\ *E-mail: bouhadidjilali@yahoo.fr \\ Tel.: +213 778101591 .
}

Received: Feb 22, 2017 / Revised: Apr 10, 2017 / Accepted: Apr 11, 2017

\begin{abstract}
Lactic acid production from renewable resources such as pods of carob alternate to derived products from oil present a growing interest, in particular for the production of biodegradable polylactic acid polymer. The carob pods syrup is a by-product composed of sugars and its use as substrate of low cost in various industries is considered however, few microorganisms consume quickly and effectively sugars to give a single product. Lactic acid bacteria were screened for sugars fermentation and Lactobacillus delbrueckii subsp. bulgaricus showed the highest levels of lactic acid production. The physicochemical analysis of carob pods syrup showed that it presents a suitable quality. The micro-organism implemented is kind Lactobacillus delbrueckii subsp. bulgaricus, cultivated in bathe fermentation. Three culture mediums were tested, the carob syrup enriched with sweet cheese whey (CS+SCW), carob syrup enriched with Tween 80 (CS+T80) and carob syrup enriched with sweet cheese whey + Tween 80 (CS+SCW+T80), the addition of the growth factors improve the culture, that is why the production of lactate is very important improved $52.76 \mathrm{~g} / \mathrm{l}$.
\end{abstract}

Key words: Ceratonia siliqua, Lactobacillus delbrueckii subsp. bulgaricus, lactic acid, carob pods.

\section{INTRODUCTION}

The carob tree (Ceratonia siliqua L.), belonging to the family Cesalpiniaceae (sub-family: Leguminosae), is widely used in the Mediterranean regions (Batlle and Tous, 1997) cultivated for ornamental and industrial purposes (Yousif and Alghzawi, 2000).

World production is estimated at about 422333.66 ton per year, and the main producers for pulp, seeds, respectively, are Spain (36\%, $28 \%)$, Morocco $(24 \%, 38 \%)$, Italy $(10 \%, 8 \%)$, Portugal $(10 \%, 8 \%)$, Greece $(8 \%, 6 \%)$, Turkey $(4 \%, 6 \%)$ and Cyprus $(3 \%, 2 \%)$ of the world production. Carob tree has an economic and environmental importance in Algeria. It is used in reforestation of arid and degraded areas and also as for ornamental purposes.
The pulp and the seeds have some interesting properties and are often used in food and pharmacological industry (Batlle and Tous, 1997; Markis and Kefalas, 2004). Carob pods are also characterized by high sugar content (500 g/kg) (NAS, 1979; Petit and Pinilla, 1995; Batlle and Tous, 1997; Markis and Kefalas, 2004). Carob pulp is a good source of protein (2.7$7.6 \%)$ but it is poor in lipid (0.4-0.8\%) (Biner et al 2007).

In Algeria, the carob tree is frequently cultivated in the Saharan Atlas and it is common in the tell, is found naturally in association with the almond tree, Olea europea and Pistacia atlantica in hot semiarid floors Subhumid and humid.

The pulp and the seeds are valorized in different applications, seeds powder can be used in baby 
foods to prevent vomiting (Sabra and Walter, 2001). The locust bean gum is also applied in pharmaceutical industry as drug delivery (Sandolo et al 2007).

Chemical composition of carob had been studied extensively for different countries of the Mediterranean area. It had been observed that this composition is depending not only on technological factors such as the extraction and analytical methodologies, but also on the genotype of the plant, the geographical origin, the climate conditions and the harvesting and storage procedures [Batlle and Tous, 1997; Biner et al 2007; Owen et al 2003; Naghmouchi et al 2009; Sidina et al 2009]. However, in spite of the great interest to carob and their use in different applications, few studies are available on carob.

Lactic acid production from renewable resources such as wheat carob as alternate to derived products from oil present a growing interest, in particular for the production of biodegradable polylactic acid polymer. Carob Pods is a byproduct composed of sugars and its use as substrate of low cost in various industries is considered however, few microorganisms consume quickly and effectively sugars to give a single product. Lactic acid bacteria were screened for sugars fermentation and Lactobacillus delbrueckii subsp. bulgaricus showed the highest levels of lactic acid production.

Lactic fermentation is the main activity of lactic bacteria, while Lactobacillus delbrueckii subsp. bulgaricus is the major species used in lactic acid making. It utilizes sucrose, glucose and fructose carbon sources to produce lactic acid. Indeed, this carob is rich sugars that could be used as carbonaceous source of fermentation for the production of the biomass and lactic acid. The objective of this study is the utilization of the Carob Pods Syrup as the substrate for the growth of Lactobacillus delbrueckii subsp. bulgaricus and the production of lactic acid.

\section{MATERIALS AND METHODS Chemicals \\ Vegetable material}

The carob (Ceratonia siliqua L.) used in current experiments was harvested in the month of 2015 from the region of Mohammadia (Mascara, Algeria) (Figure 1).

The choice of this variety is justified by its availability and important nutritive value, especially the one of reducing fermentable

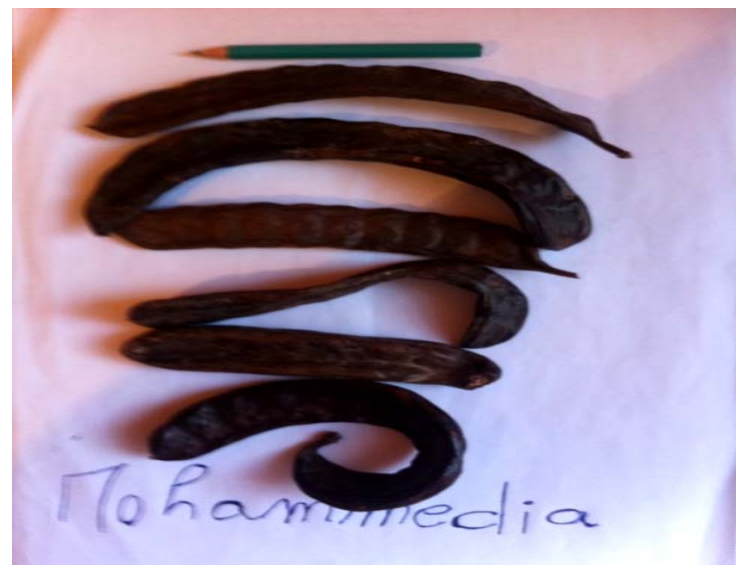

Fig. 1. Carob pods (Ceratonia siliqua L.) of the Mohammadia area (Mascara, Algeria)

sugars such as glucose and sucrose. 20 pods were randomly collected. This choice was made based on the study on Morphological characteristics (whole pod weight, Weight of pulp, Seed weight, length of pod). Length (cm) of pod was measured using a measuring tape, whereas width $(\mathrm{cm})$ was assessed with the Vernier caliper. Weight (g) of pods and kernels were taken using a balance. Results of morphological characteristics of carob pod are presented in Table 1.

Table 1. Morphological characteristics of the carob pods

\begin{tabular}{|c|c|}
\hline Parameters & Average volume \\
\hline Number of sees/pod & $11 \pm 1.49$ \\
\hline Whol pod weight (g) & $12.71 \pm 1.52$ \\
\hline Wight of pulp (g) & $5.38 \pm 1.36$ \\
\hline Seed weight(g) & $0.68 \pm 0.02$ \\
\hline Lengh of pod (cm) & $13.43 \pm 0.760$ \\
\hline Wigth of pod (cm) & $2.16 \pm 0.29$ \\
\hline Lengh of the seed (mm) & $10.3 \pm 0.67$ \\
\hline Width of the seed & $7.9 \pm 0.99$ \\
\hline Thickness of the seed & $0.21 \pm 0.01$ \\
\hline Length report/Width & 6.23 \\
\hline Seed report/carob (\%) & 5.35 \\
\hline Report pulp / pod (\%) & 42.32 \\
\hline Pulp/seed & 7.91 \\
\hline
\end{tabular}

\section{Extraction and analysis of carob pods syrup}

To determine the chemical composition of carob pulp, Carob pods were chopped into small particles $(1-3 \mathrm{~cm})$. One liter of hot water at 80 $85^{\circ} \mathrm{C}$ was added to $200 \mathrm{~g}$ of carob pods, homogenized and through a cloth. The syrup obtained was centrifuged at $15000 \mathrm{rpm}$ for 10 min to separate the cellulose debris. The collected supernatant was used as culture medium. The syrup is fixed in a pH 6 and 
sterilized during $20 \mathrm{~min}$ at $120^{\circ} \mathrm{C}$. The extraction parameters were obtained from method advocated by Turhan and co-workers in 2010 . $\mathrm{pH}$ is measured using a $\mathrm{pH}$ meter and density was determined by density meter. Concentration of lactic acid was determined by acidity titration with $0.1 \mathrm{~N} \mathrm{NaOH}$. Total nitrogen of carob and protein content was determined by the method of Kjeldahl digestion and distillation apparatus (AOAC, 2007). Total and reducing sugars were determined colorimetrically at $480 \mathrm{~nm}$ (DuBois et al 1956). The ash content of the carob was determined according to the AOAC official method 972.15 by incineration one gram of syrup at a temperature of $600^{\circ} \mathrm{C}$ during $3 \mathrm{~h}$. Moisture and dry matter were determined by drying $10 \mathrm{ml}$ of syrup at $105^{\circ} \mathrm{C}$ during $18 \mathrm{~h}$. The mineral salts are determined according to the methods advocated by Sawaya and co-workers in 1983.

\section{Leavens used}

Lactobacillus delbrueckii subsp. bulgaricus were obtained from Giplait of Mascara (Algeria). The strain of Lactobacillus is homo fermentative (homolactic) which means that more than 90\% of metabolits are produced by the lactic fermentation.

\section{The insulation of the lactic flora}

The strain was inoculated at a rate of $1 \%$ in tubes containing $10 \mathrm{ml}$ of sterile skimmed milk and incubated at $30^{\circ} \mathrm{C}$ until the coagulation of milk, then sown by streaking on MRS medium. The enrichment of Lactobacillus delbrueckii subsp. bulgaricus was carried out using MRS broth.

\section{Microorganism and growth conditions}

Lactobacillus delbrueckii subsp. bulgaricus, a homofermentative lactic acid producer, was used. Stock cultures were stored in MRS medium with $25 \%(\mathrm{v} / \mathrm{v})$ glycerol at $-20^{\circ} \mathrm{C}$. The inoculum was prepared by transferring glycerol stock culture to Erlenmeyer flasks containing $100 \mathrm{ml}$ of liquid MRS medium for preculture. The flask was subsequential incubated at $38^{\circ} \mathrm{C}$ for $12 \mathrm{~h}$, the time needed for the microorganism to reach the exponential growth phase. Then, the culture was inoculated to Erlenmeyer flasks containing the production medium. 10\% inoculums grown in the MRS medium was used in all fermentations. Flask experiments were carried out in $250 \mathrm{ml}$ Erlenmeyer containing $100 \mathrm{ml}$ of production medium. The agitation speed and culture temperature were controlled at $150 \mathrm{rpm}$ and $38^{\circ} \mathrm{C}$ respectively.

\section{Fermentation conditions and methods}

The biochemical analysis applied on the carob pods syrup shows that it is poor in protein and fatty-acids, so the addition of these elements (growth factors) is necessary to the syrup in order to import the quantity of lactic acid. Three culture mediums were used: carob syrup with $10 \mathrm{~g}$ of sweet cheese whey $(\mathrm{CS}+\mathrm{SCW})$, carob syrup with $1 \mathrm{ml}$ of Tween80 (commercial form of oleic acid) (CS+T80) and carob syrup with 10 $\mathrm{g}$ of sweet cheese whey and $1 \mathrm{~mL}$ of Tween 80 (CS+SCW+T80). The biomass is determined by measurement of the optical density (OD) at 600 $\mathrm{nm}$ by a spectrophotometer.

The various analyses carried out allow the following time evolution of the component concentrations present in the culture medium: [Biomass: $(O D)=f(t)$, sugars: $S=f(t)$ and the lactic acid: $P=f(t)]$. From these raw data it is possible to calculate the fermentation kinetic parameters in the batch culture by the calculation of the specific rate of growth $(\mu$ in h1 ), of substrate consumption (Qs in g. $\left.^{-1} \cdot \mathrm{h}^{-1}\right)$ and lactic acid production (QL.A in g.g ${ }^{-1} \cdot \mathrm{h}^{-1}$ ).

$$
\mu=\frac{F x}{X}, Q s=\frac{r g}{X}, Q \ln a \frac{r p}{x}
$$

The maximal specific growth rate ( $\mu$ max) was determined from the slopes of the plotted linear curve: $\operatorname{LnX} / \mathrm{XO}=\mathrm{f}(\mathrm{t})$. The biomass $(\mathrm{Yx} / \mathrm{s})$ and products $(\mathrm{Yp} / \mathrm{s})$ yields are defined as the mass ratios in biomass and metabolites formed per gram of consumed carbonaceous substrate.

\section{RESULTS AND DISCUSSION}

\section{Biochemical composition of carob pods syrup}

The carob pods syrup which has been the subject of our work has high water content $83.66 \%$ (Table 2), we agree that a product with high water content facilitates lactic acid bacteria proliferation and helps for a better substrateenzyme contact. Carob pods syrup obtained is very rich in sugars (31.82 $\mathrm{g} / \mathrm{l})$ and vitamin $C$ $(0.07 \mathrm{~g} / \mathrm{l})$. The carob syrup is poor with protein $0.16 \mathrm{~g} / 100 \mathrm{ml}$. An ash content of $0.6 \%$ indicates its richness of minerals including potassium. The date, with a $\mathrm{pH}$ of 5.5 , seems to be favorable for the growth of Lactobacillus delbrueckii subsp. bulgaricus. The carob syrup. An ash content of $(2 \mathrm{~g} / \mathrm{l})$ indicates its richness of minerals. 
Table 2. Biochemical composition of the carob pods syrup

\begin{tabular}{|c|c|}
\hline Biochemical composition & Average \\
\hline Dry matter & $15 \mathrm{~g} / 100 \mathrm{ml}$ \\
\hline Moisture & $83.66 \%$ \\
\hline $\mathrm{pH}$ & 5.08 \\
\hline Acidities & $27 \mathrm{m.eq} \%$ \\
\hline Density & $2.19 \mathrm{Kg} / \mathrm{m}^{3}$ \\
\hline Total sugar & $31.82 \mathrm{~g} / \mathrm{l}$ \\
\hline Proteins & $0.16 \mathrm{~g} / 100 \mathrm{ml}$ \\
\hline Vitamin C & $0.07 \mathrm{~g} / \mathrm{l}$ \\
\hline Ashes & $0.6 \%$ \\
\hline
\end{tabular}

\section{Results of the fermentation kinetics}

The analysis applied on the carob pods syrup shows that it is poor, with protein, minerals such and fatty-acids, so the addition of these elements (growth factors) is necessary to the syrup in order to import this quantity of lactic acid. According to Fidan and Sapundzhieva (2015), carob fruit (pulps and seeds) and flour are rich in carbohydrates.

According to the literature data, many factors affect the chemical composition of the fruit as well as its mineral content, for example, temperature, dryness (Nunes et al 1992), irrigation and fertilization (Correia and MartinsLoucao, 1997) and salinity (El-Dengawy et al 2011).

Finally, the biochemical analysis show that it can constitute a fermentation medium of good quality. The results of the three fermentations, of the pods enriched with sweet cheese whey (CS+SCW), pods syrup enriched with tween 80 and pods syrup with sweet cheese whey and tween $80(\mathrm{CS}+\mathrm{SCW}+\mathrm{T} 80)$ by Lactobacillus delbrueckii subsp. bulgaricus are presented in Figures 2-4, which present the evolution of the concentrations in biomass, sugars and lactic acid for the pods syrup fermentation, we observe a weak initial concentration of biomass is of 0.2 then it increased after $36 \mathrm{~h}$ of fermentation until 1.6 , after that we recorded the fall of biomass till a value of 0.5 (CS + T80).

The results clearly indicated that the highest amount of biomass and lactic acid were obtained with the syrup carob enriched with sweet cheese whey and tween 80. In the medium enriched with sweet cheese whey, (CS with SCW), and two components (SCW and T80), the lactic acid rate evolves gradually to achieve the end of fermentation $52.76 \mathrm{~g} / \mathrm{l}$. The addition of Tween 80 and sweet cheese whey in carob syrup increase the lactic acid production. However, decreasing of sugar rates is very faster in the medium supplemented with T80 and SWC. Where the Lactobacillus delbrueckii subsp. bulgaricus consumes about half quantity of initial total sugars, during $35 \mathrm{~h}$ of fermentation from an initial quantity of $31.82 \mathrm{~g} / \mathrm{l}$ of sugars, it remains $5.6 \mathrm{~g} / \mathrm{l}$ which implies an amount of $27.6 \mathrm{~g} / \mathrm{l}$.

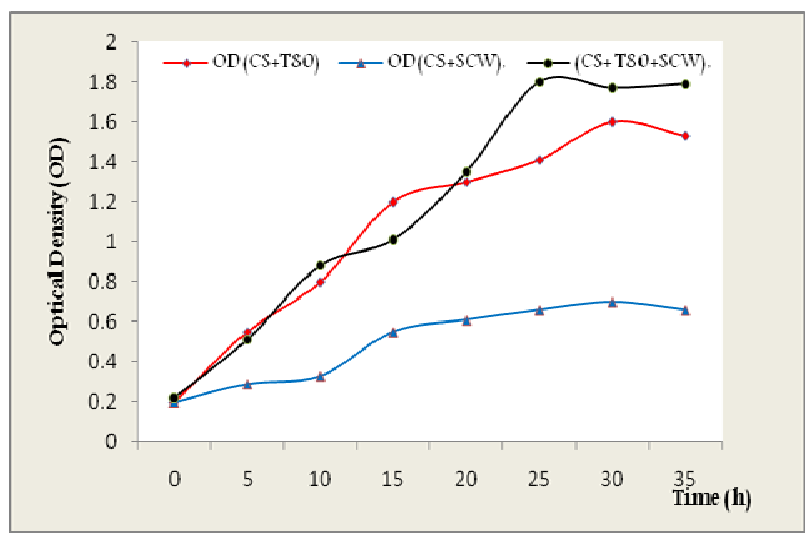

Fig 2. Evolution of OD during the culture of Lactobacillus delbrueckii subsp. bulgaricus on mediums containing carob syrup + T80 $(\mathrm{CS}+\mathrm{T} 80)$, carob Syrup + sweet cheese whey (CS+SCW) and carob syrup + T80 + sweet cheese whey $(\mathrm{CS}+\mathrm{T} 80+\mathrm{SCW})$.

In parallel, in the medium enriched with tween 80 and the production of the lactic acid starts from a value of $6 \mathrm{~g} / \mathrm{l}$ and reach $17 \mathrm{~g} / \mathrm{l}$ of lactate after $35 \mathrm{~h}$ of fermentation. In parallel and since there was an evolution of biomass and lactic acid, there was a consumption of sugars, it remained at the end of fermentation $10 \mathrm{~g}$ sugars and $8 \mathrm{~g} / \mathrm{l}(\mathrm{CS}+\mathrm{SWC})$.

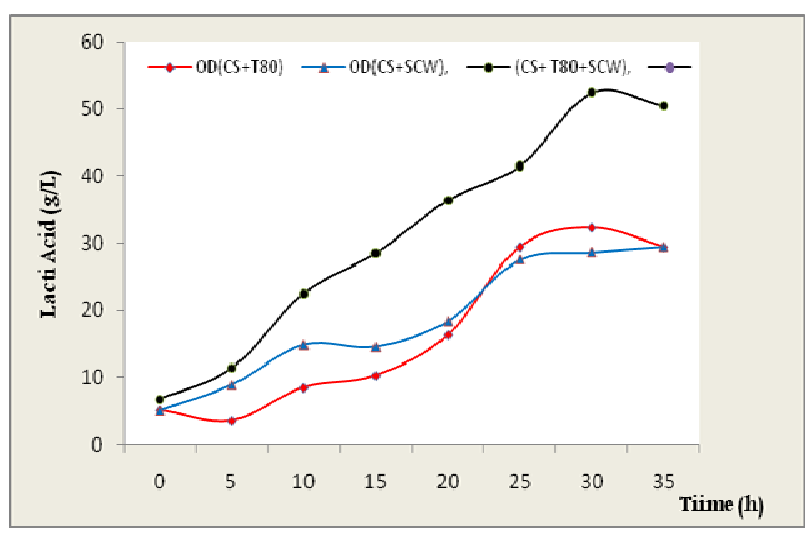

Fig. 3. Evolution of lactic acid in g/l during the culture of Lactobacillus delbrueckii subsp. bulgaricus on mediums containing carob syrup + T80 (CS+T80), carob syrup + sweet cheese whey $(\mathrm{CS}+\mathrm{SCW})$ and carob syrup $+\mathrm{T} 80+$ sweet cheese whey $(\mathrm{CS}+\mathrm{T} 80+\mathrm{SCW})$. 
However for fermentation on medium containing pods syrup with tween 80 an SCW, the optical density of Lactobacillus delbrueckii subsp. bulgaricus started with an initial concentration 0.2 to reach a maximum value of 1.8 , then a decrease of the biomass up to a value of 0.5 was recorded. This decreasing in biomass correspond to the phase of decline which is due to the impoverishment of nutriments from the medium and the accumulation of metabolism wastes causing important physic chemical changes and bacteria lysis.

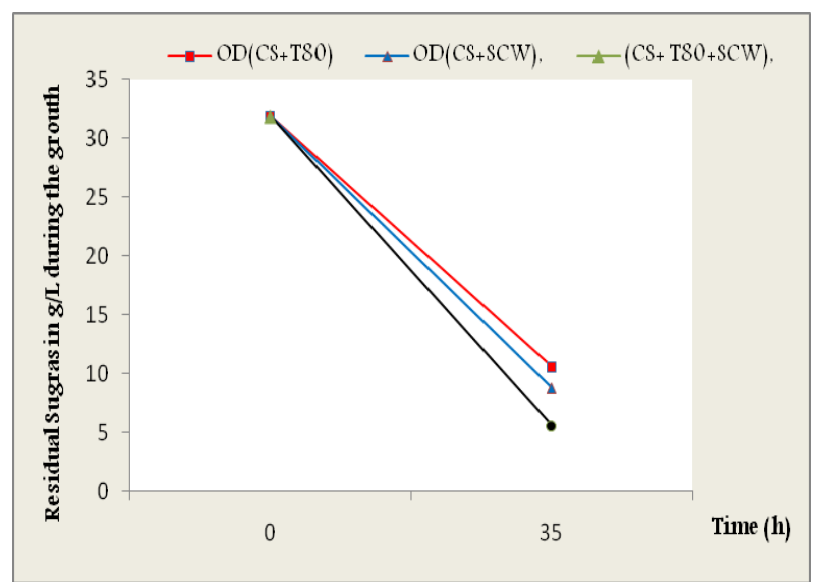

Fig. 4. Evolution of residual sugars in g/l during the culture of Lactobacillus delbrueckii subsp. bulgaricus on mediums containing carob syrup + T80 (CS T80), carob syrup + sweet cheese whey $(\mathrm{CS}+\mathrm{SCW})$ and carob syrup $+\mathrm{T} 80+$ sweet cheese whey $(\mathrm{CS}+\mathrm{T} 80+\mathrm{SCW})$.

In the case of enriched (CS with SWC), we observe a low initial concentration of biomass and in the end of fermentation optical density reaches a maximum value 0.7 . Sweet cheese

\section{REFERENCES}

AOAC - Official methods of analysis of AOAC International. Gaithersburg. Maryland, 2007; 2:955.04-945.46.

Batlle I, Tous J. Carob tree (Ceratonia siliqua L.) Promoting the conservation and use of underutilized and neglected crops. 17. Institute of Plant Genetics and Crop Plant Research, Gatersleben/International Plant Genetic Resources Institute, Rome, Italy, 1997.

Biner B, Gubbuk H, Karhan M, Aksu M, Pekmezci M. Sugar profiles of the pods of cultivated and wild types of carob bean (Ceratonia siliqua L.) in Turkey. Food Chem. 2007; 100(4):1453-5. [DOI: 10.1016/j.foodchem.2005.11.037]

Bouhadi D, Abbouni B, Hariri A, Ibri K, Ouiss N. Study of the behaviour of Lactobacillus delbrueckii subsp. bulgaricus in Date syrup in batch fermentation with controlled $\mathrm{pH}$. $J$. Biotechnol. Biomaterial. 2012;2(2):129. [DOI: 10.4172/ 21 55-952X.1000129]

Correia PJ, Martins-Loucao MA. Leaf nutrient variation in mature carob (Ceratonia siliqua) trees in response to irrigation and fertilization. Tree Physiol. 1997; 17(12): 813-9. whey (source of soluble proteins) is essential for growth of lactic acid. Comparing the results for both fermentations indicated that the addition of growth factors in culture medium has a positive and beneficial effect on fermentation, since the growth rate and lactic acid production increase after the enrichment of carob pods syrup. The addition of Tween 80 allows better cells excretion of lactic acid by creating pores in the membrane and plays the role of surfactant which makes a good contact between bacteria and nutriments, and for more it is considered as a source of carbon and energy for electrons (Bouhadi et al 2012). From these results, the enriched mediums present an interesting result. Moreover, lactic acid bacteria are unable to synthesize amino acids from simple inorganic nitrogen source; Lactobacillus delbrueckii subsp. bulgaricus have needs glutamic acid, histidine, methionine, valine, leucine and tryptophan. Once the amino acid exhausted, the lactic acid bacteria use the molecular weight of peptides of less than 1500 daltons. The peptides are assimilated either by hydrolysis outside of the cell and transported form of amino acids or with active system in the absence of peptidase.

\section{CONCLUSION}

The present work has shown that the valorization of dates syrups, packaged industrially to $32.82 \mathrm{~g} / \mathrm{l}$ by the Tunisian agrofood industry, lactic acid is possible by yeasts. We obtained $24 \mathrm{~g} / \mathrm{l}$ of lactic acid after $35 \mathrm{~h}$ of fermentation by Lactobacillus delbrueckii subsp. bulgaricus which consumes $27.22 \mathrm{~g} / \mathrm{l}$ of the sugars of a culture medium based on syrup of carob.

DuBois M, Gilles KA, Hamilton JK, Rebers PA, Smith F. Colometrie method for determination of sugars and related substances. Anal. Chem. 1956;28(3):350-6. [DOI: 10.1021/ac60111a017]

El-Dengawy ERFA, Hussein AA, Alamri SA. Improving growth and salinity tolerance of carob seedlings (Ceratonia siliqua L.) by Azospirillum inoculation. Am.Euras. J. Agric. Environ. Sci. 2011;11(3):371-84.

Fidan H, Sapundzhieva T. Mineral composition of pods, seeds and flour of grafted carob (Ceratonia siliqua L.). fruits. Sci. Bull. Series F. Biotechnol. 2015;XIV:136-9.

Markis DP, Kefalas P. Carob pods (Ceratonia siliqua L.) as a source of polyphenolic antioxidants. Food Technol. Biotechnol. 2004;42(2):105-8.

Sawaya WN, Safi WM, Black LT, Mashadi AS, Al-Muhammad MM. Physical and chemical characterization of the major Date varieties grown in Saudi-Arabia, 2: Sugars, tannins, vitamins A and C. Date Palm J. 1983;2(2):183-96.

Naghmouchi S, Khouja ML, Romero A, Tous J, Boussaid M. Tunisian carob (Ceratonia siliqua L.) populations: 
Morphological variability of pods and kernel. Sci. Hort. 2009;121(2):125-30. [DOI: 10.1016/j.scienta.2009.0 2.026]

Nunes MA, Ramalho JDC, da Silva Rijo P. Seasonal changes in some photosynthetic properties of Ceratonia siliqua (carob tree) leaves under natural conditions. Physiol. Plant. 1992;86(3): 381-7. [DOI: 10.1111/j.1399-3054.19 $9 \backslash 2 . t b 01333 . x]$

Owen RW, Haubner R, Hull WE, Erben G, Spiegelhalder B, Bartsch H, Haber B. Isolation and structure elucidation of the major individual polyphenols in carob fibre. Food Chem. Toxicol. 2003;41(12):1727-38. [DOI: 10.1016/S02 78-6915(03)00200-X]

Petit MD, Pinilla JM. Production and purification of a sugar syrup from carob pods. LWT-Food Sci. Technol. 1995;28(1):145-52. [DOI: 10.1016/S0023-6438(95)8002 7-1]

Sabra A, Walter S. Non-wood Forest Products in the Near East: A Regional and National Overview. Food and
Agriculture Organization of the United Nations (FAO), Non-Wood Forest Products Programme. 2001; Working Paper FOPW/01/2.

Sandolo C, Coviello T, Matricardi P, Alhaique F. Characterization of polysaccharide hydrogels for modified drug delivery. Eur. Biophys. J. 2007;36(7):693-700. [DOI: 10.1007/s00249-007-0158-y]

Sidina MM, El Hansali M, Wahid N, Ouatmane A, Boulli A, Haddioui A. Fruit and seed diversity of domesticated carob (Ceratonia siliqua L.) in Morocco. Sci. Hort. 2009;123(1):110-6. [DOI: 10.1016/j.scienta.2009.0 7.009]

Turhan I, Bialka KL, Demirci A, Karhan M. Ethanol production from carob extract by Saccharomyces cerevisiae. Biores. Technol. 2010;101(14):5290-6. [DOI: 10.1016/j.biortech.2010.01.146]

Yousif AK, Alghzawi HM. Processing and characterization of carob powder. Food Chem. 2000;69(3):283-7. [DOI: 10.10 16/S0308-8146(99)00265-4] 